\title{
Effects of Incubator Carbon Dioxide and Oxygen Levels, and Egg Weight on Broilers' Hatchability of Fertile Eggs
}

Original Article

mAuthor(s)

Okur N'_ (iD https://orcid.org/0000-0003-2431-0313 Department of Poultry Science, Faculty of Agriculture and Natural Sciences, Bolu Abant Izzet Baysal University, Bolu/Turkey.

\section{-Mail Address}

Corresponding author e-mail address Nezih Okur

Bolu Abant Izzet Baysal University Department of Poultry Science, Faculty of Agriculture and Natural Sciences, Golkoy Campus Bolu 14280 - Turkey.

Phone: +905309681614

Email: nezihokur@ibu.edu.tr

\section{aKeywords}

Broiler, carbon dioxide, egg weight, incubation, oxygen.

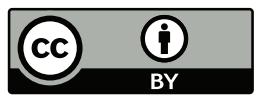

Submitted: 08/March/2019 Approved: 26/June/2019

\section{ABSTRACT}

This study investigated the effects of incubator carbon dioxide $\left(\mathrm{CO}_{2}\right)$ and oxygen $\left(\mathrm{O}_{2}\right)$ levels, and egg weight (EW) on embryo mortality (EM) and hatchability of fertile eggs (HFE). A total of 1920 hatching eggs were obtained from a middle-aged (41 weeks) ROSS 308 broiler breeder flock. The eggs were classified according to EW as heavy $(69.63 \pm 0.09 \mathrm{~g})$, medium $(65.20 \pm 0.04 \mathrm{~g})$ and light $(61.11 \pm 0.08$ g) and randomly allocated to four separate identical incubators. To these incubators, four different incubator ventilation programmes (IVP) classified as control $\left(\mathrm{C} ; 0.7 \% \mathrm{CO}_{2}\right.$ and $\left.20.9 \% \mathrm{O}_{2}\right)$, high $\mathrm{CO}_{2}(\mathrm{HC}$; $1.1 \% \mathrm{CO}_{2}$ and $\left.20.3 \% \mathrm{O}_{2}\right)$, high $\mathrm{O}_{2}\left(\mathrm{HO} ; 0.6 \% \mathrm{CO}_{2}\right.$ and $\left.22.0 \% \mathrm{O}_{2}\right)$, and high $\mathrm{CO}_{2}+\mathrm{O}_{2}\left(\mathrm{HCO} ; 0.9 \% \mathrm{CO}_{2} 21.0 \% \mathrm{O}_{2}\right)$ were applied, and EM and HFE were examined. IVP affected EM and HFE; a higher rate of early EM and a lower rate of HFE were obtained from the HO group compared to the HCO group, and a lower rate of HFE was observed in the $\mathrm{HO}$ group than to the $\mathrm{C}$ group $(p<0.05)$. An association was found between EW and IVP $(p<0.05)$, being more evident in early EM for light eggs. Consequently, IVP; i.e., different $\mathrm{CO}_{2}$ and $\mathrm{O}_{2}$ levels in the incubator affected the hatching results. This is considered to be due to the altitude of the experiment $(724 \mathrm{~m})$ and the uniform eggs being obtained from the same middle-aged flock, and incubator $\mathrm{O}_{2}$ levels should be taken into consideration, as well as $\mathrm{CO}_{2}$.

\section{INTRODUCTION}

Hatching performance varies according to management strategies, characteristics of breeders, such as genetics, age and health, maintenance and feeding conditions, and hatching egg weight (EW) (Meijerhof, 2009; Elibol \& Turkoglu, 2014).

EW is an important factor affecting hatchability $(\mathrm{H})$ and post-hatch performance of broilers. It was reported that $H$ decreases as $E W$ increases (Huwaida et al., 2015). For example, egg weight ranges from $50.4 \mathrm{~g}$ (26 week age) to $70.4 \mathrm{~g}$ (64 week age) (Aviagen, 2011), hatchability ranges from $75.6 \%$ (26 week age) to $71.7 \%$ (64 week age) to performance objectives for Ross 308 parent stock (Aviagen, 2011). Accordingly, early stage embryonic mortality (EEM) and mid stage embryonic deaths (MEM) and late stage+pipped but unhatched embryonic mortality (LPU) are changed to stage of embryonic development to BA and the targets in young (25-30week), peak (31-45 week) post-peak (46-50 week) and old (51-60week) breders were determined for EEM (5.5, 3.5, 5 and 8.0), MEM (1.0, 0.5, 1.0 and 1.0) and $\operatorname{LPU}(5.0,3.5,3.5$ and 4.5) respectively (Tullet, 2009). In flocks at the same age, this could arise from early stage embryo mortality (EM) (Abiola et al., 2008) or both early and late stage embryo mortalities due to air circulation problems in the incubator (Elibol \& Brake, 2008). In large eggs, it was reported 
that the thermoregulation stress of the embryo might occur due to the increase in water loss (Lourens et al., 2005). Thus, the authors suggested paying greater attention to air circulation in incubators and decreasing the temperature during the second stage of incubation for heavier eggs.

It is known that during the incubation period, as the embryo develops, oxygen $\left(\mathrm{O}_{2}\right)$ consumption and carbon dioxide $\left(\mathrm{CO}_{2}\right)$ production increase. Therefore, the levels of $\mathrm{CO}_{2}$ and $\mathrm{O}_{2}$ in the incubator are also crucial factors for embryonic development and may affect performance both at hatching as well as post-incubation (Decuypere et al., 2001; Fernandes et al., 2014). It is known that the oxygen demand and tolerance of the embryo is the lowest in the first five days of incubation and both increase over time (Taylor et al., 1971; Everaert et al., 2007). The pore numbers and eggshell conductance also affect this situation, and it has been suggested that as eggshell conductance rises with the increase in the egg size, the gas exchange is also increased ( $\mathrm{Ar}$ et al., 1974; Visschedijk, 1991). As a result, late-stage EMs are more commonly seen among eggs with high eggshell conductance (Bamelis, 2003).

In the literature, conflicting data have been obtained from the studies investigating the effects of $\mathrm{CO}_{2}$ and $\mathrm{O}_{2}$ on the hatching performance (Onagbesan et al., 2007; Piestun et al., 2008; Celen et al., 2009). However, it is known that $\mathrm{H}$ decreases with the increasing altitude, depending on the level of $\mathrm{O}_{2}$ in the air, affecting $\mathrm{H}$ and chick quality. $\mathrm{O}_{2}$ content in normal air is about 21-22\% (Stock \& Metcalfe, 1984; Cobb, 2013) and according to several recent studies, hatching and field performance is adversely affected by low $(<17 \%)$ and high (25\%) $\mathrm{O}_{2}$ levels (Stock \& Metcalfe, 1984; Lourens et al., 2007; Celen et al., 2009; Molenaar et al., 2010). In areas at high altitudes, such as India and South America (3500-4000 m), very low hatchability rates, such as $20 \%$ have been detected under normal conditions (Ahmed et al., 2013). To overcome this problem, additional systems increasing the $\mathrm{O}_{2}$ levels of the air in incubators are commonly used in these areas. It has been suggested that $\mathrm{O}_{2}$ levels should be increased by $8.5 \%$ in areas at altitudes higher than $750 \mathrm{~m}$ (Cobb, 2013) and 13.8\% in those higher than $1500 \mathrm{~m}$ (Tullet, 2013). The $\mathrm{CO}_{2}$ tolerance of the embryo increases over time in parallel with the rising $\mathrm{O}_{2}$ level. According to the previous studies, when the normal $\mathrm{CO}_{2}$ level $(1.0 \%)$ is increased to $1.5 \%$ during the first 10 days of incubation, embryonic growth and early hatches gradually improve and hatchability is facilitated (Buys et al., 1998; Tona et al., 2007; Tona et al., 2013; Tong et al., 2015). Nevertheless, these effects are considered to vary between chicken lines (De Smit et al., 2008; Tona et al., 2013). High $\mathrm{CO}_{2}$ after the first 10 days of incubation also have different effects on incubation and post-hatch performance (Everaert et al., 2007; Tona et al., 2013; Fernandes et al., 2014; Ozlu et al., 2019), depending on the level of exposure and duration of the $\mathrm{CO}_{2}$ application.

The hypothesis of the study was that the differences in the $\mathrm{CO}_{2}$ and $\mathrm{O}_{2}$ levels in the incubator with $\mathrm{EW}$ would affect broilers' EM and hatchability of fertile eggs (HFE) at a certain altitude (724 m) and this effect would be reversed with the addition of $\mathrm{O}_{2}$.

\section{MATERIALS AND METHODS}

This study was performed in accordance with the Animal Welfare Legislation of Turkey and all procedures involving the handling of eggs and chicks were approved by the Animal Ethics Committee of Bolu Abant Izzet Baysal University (Decision No: 2015/45 of Dec. 30, 2015). This research was conducted within the scope of the BAP project numbered 2016.10.03.990, which also provided funding for the equipment used.

This research was conducted in Bolu, a province in Turkey where more than $25 \%$ of domestic broiler production is undertaken. The city is located at an altitude of $724 \mathrm{~m}$ similar to many places where hatcheries are built both in Turkey and around the world.

\section{Equipment used in the trial}

For the experiment, a total of 1950 hatching eggs were collected from the middle-aged (41 weeks) ROSS 308 broiler breeder flocks of a commercial company in Bolu. Dirty, cracked, wrinkled and thin-shelled eggs were considered as unsuitable and discarded. The remaining 1920 hatching eggs were individually numbered and weighed $( \pm 0.1 \mathrm{mg})$ by an analytical balance (Radwag AS 220.R2, Radwag Balance and Scales, Poland) and the results were recorded.

The incubation process was carried out in the incubation laboratory of Bolu Abant Izzet Baysal University Faculty of Agriculture and Natural Sciences Department of Poultry Science using four identical incubators with a capacity of 480 chicken eggs each (Cimuka 960SH, Cimuka Ltd. Co., Turkey). The same machines were used for the whole incubation process. Each incubator was equipped with six trays with a capacity of 80 eggs, and as well as six hatch baskets with the same egg capacity. 


\section{Trial design}

In order to examine the effect of EW and eliminate or minimize its effect on other treatments, a frequency analysis was performed by Tukey's Hinges test (SPSS, 2013), and according to the frequency percentages, EW groups were formed. Then, the eggs were divided into three groups by weight as heavy $(69.6 \pm 0.1 \mathrm{~g})$, medium $(65.2 \pm 0.0 \mathrm{~g})$ and light $(61.1 \pm 0.1 \mathrm{~g})$.

A layout plan for eggs was prepared to ensure that those with similar weights would be included in the same tray, thus in the same incubator and treatment group. Once the eggs were placed in the tray according to the layout plan, the incubation process was carried out. The eggs were weighed and then placed in their allocated locations in each incubator tray according to the lay-out plan (Table 1).

Table 1 - The egg weight values obtained from the treatment groups in the experiment $(\mathrm{M} \pm \mathrm{SEM})$.

\begin{tabular}{|c|c|c|}
\hline Treatments & Egg Number & Egg Weight, g \\
\hline \multicolumn{3}{|l|}{ Main Effects } \\
\hline \multicolumn{3}{|l|}{ Egg Weight, g } \\
\hline Heavy & 640 & $69.63 \pm 0.09^{a}$ \\
\hline Medium & 640 & $65.20 \pm 0.04^{b}$ \\
\hline Light & 640 & $61.11 \pm 0.08^{c}$ \\
\hline \multicolumn{3}{|c|}{ Incubator Ventilation Program } \\
\hline Control & 480 & $65.38 \pm 0.17$ \\
\hline High $\mathrm{CO}_{2}$ & 480 & $65.24 \pm 0.18$ \\
\hline High $\mathrm{O}_{2}$ & 480 & $65.30 \pm 0.18$ \\
\hline $\operatorname{High~} \mathrm{CO}_{2}+\mathrm{O}_{2}$ & 480 & $65.31 \pm 0.18$ \\
\hline \multicolumn{3}{|l|}{ Interaction EW X IVP } \\
\hline Heavy Egg C & 160 & $69.65 \pm 0.19$ \\
\hline Heavy Egg HC & 160 & $69.55 \pm 0.18$ \\
\hline Heavy Egg $\mathrm{HO}$ & 160 & $69.73 \pm 0.18$ \\
\hline Heavy Egg HCO & 160 & $69.57 \pm 0.19$ \\
\hline Medium Egg C & 160 & $65.24 \pm 0.07$ \\
\hline Medium Egg HC & 160 & $65.16 \pm 0.08$ \\
\hline Medium Egg $\mathrm{HO}$ & 160 & $65.15 \pm 0.08$ \\
\hline Medium Egg HCO & 160 & $65.24 \pm 0.08$ \\
\hline Light Egg $C$ & 160 & $61.04 \pm 0.16$ \\
\hline Light Egg HC & 160 & $61.00 \pm 0.17$ \\
\hline Light Egg $\mathrm{HO}$ & 160 & $61.04 \pm 0.17$ \\
\hline Light Egg $\mathrm{HCO}$ & 160 & $61.34 \pm 0.15$ \\
\hline \multicolumn{3}{|l|}{$p$ Values } \\
\hline EW & & 0.000 \\
\hline IVP & & 0.690 \\
\hline Interaction, (EW x IVP) & & 0.764 \\
\hline
\end{tabular}

EW: Egg Weight, IVP: Incubator ventilation program, C: Control $\left(0.7 \% \mathrm{CO}_{2}\right.$ and $\left.20.9 \% \mathrm{O}_{2}\right), \mathrm{HC}$ : High $\mathrm{CO}_{2}\left(1.1 \% \mathrm{CO}_{2}\right.$ and $20.3 \%$ $\left.\mathrm{O}_{2}\right)$, HO: High $\mathrm{O}_{2}\left(0.6 \% \mathrm{CO}_{2}\right.$ and $\left.22.0 \% \mathrm{O}_{2}\right), \mathrm{HCO}$ : High $\mathrm{CO}_{2}+$ $\mathrm{O}_{2}\left(0.9 \% \mathrm{CO}_{2} 21.0 \% \mathrm{O}_{2}\right)$.

abc Different superscript letters show that difference between means of groups are statistically significant $(P<0.05)$.

It is known that the $\mathrm{O}_{2}$ level should be increased by about $8.5 \%$ in regions higher than $750 \mathrm{~m}$ (Cobb,
2013; Tullet, 2013) and the experiment was carried out at an altitude of $724 \mathrm{~m}$. It has also been reported that increasing the $\mathrm{CO}_{2}$ level to about 1.0-1.5 \% on the $10^{\text {th }}$ day of incubation improves hatchability (Buys et al., 1998; Tona et al., 2007; Tong et al., 2015), which varies according to the chicken lines (De Smit et al., 2008; Tona et al., 2013). In the light of this information, in the incubation test trials performed before the experiment, the main air inlets were closed and the $\mathrm{CO}_{2}$ and $\mathrm{O}_{2}$ levels in the machine were monitored and recorded. During these test trials, in the first 10 days of incubation, the $\mathrm{CO}_{2}$ levels increased up to $1.6 \%$ and the $\mathrm{O}_{2}$ levels decreased to $20.2 \%$. After the air inlets were opened, the $\mathrm{CO}_{2}$ levels decreased to $0.7 \%$ and the $\mathrm{O}_{2}$ levels increased up to $20.7 \%$. According to the results of the test trials and the literature mentioned above, incubator ventilation program (IVP)treatment groups were designed for the experiment.

The treatment groups were determined as heavy, medium and light for $\mathrm{EW}$; and control (C), high $\mathrm{O}_{2}$ $(\mathrm{HO})$, high $\mathrm{CO}_{2}(\mathrm{HC})$ and high $\mathrm{CO}_{2}+$ high $\mathrm{O}_{2}(\mathrm{HCO})$ for the IVP. In each treatment group, a single tray was taken as a replicate (Table 1). When the hatching eggs were placed in the trays according to the trial design, the differences between the means of the EW treatment groups (heavy, medium and light) were found to be significant $(p=0.000)$; however, the differences between the IVP treatment groups $(C, H C$, $\mathrm{HO}$ and $\mathrm{HCO}$ ) were not statistically significant ( $p>0.05$ ) as expected and planned.

\section{Incubation period}

The eggs were stored for two days before incubation and the storage room temperature was kept at $18^{\circ} \mathrm{C}$ and the humidity at around $75 \%$. After the storage period, setter trolleys with pre-set egg trays were randomly placed in the four identical incubators. Before the incubation period, the incubators were kept at $24^{\circ} \mathrm{C}$ for six hours to preheat the eggs.

A total of 12 eggs from each incubator, 2 eggs from each tray were measured for EST values twice a day (9:00 and 17:00) by using an infrared ear thermometer (Braun Thermoscan 7 IRT6520, Braun GmbH, Deutschland) and these values were recorded and utilised to determine the optimal incubator settings. Then the mean EST values were calculated, and in case of any deviation from the expected temperature, the incubators' temperature settings were immediately adjusted as required. During the incubation period, all incubators were operated to achieve an eggshell temperature (EST) of $37.78^{\circ} \mathrm{C}\left(100.0^{\circ} \mathrm{F}\right)$. 
The relative humidity value in the incubators was maintained as $57 \%$ until transfer, then increased from $57 \%$ to $58 \%$ during the transfer, $60 \%$ during pipping and $70 \%$ during hatching. Also, the moisture of the incubation room was adjusted to $50 \%$ using two cold and warm humidifiers equipped with an ionizer humidificator (Weewell WHC752, Foshan Samyo Electronic Co. Itd., China) to ensure that the machine humidity was kept at $57 \%$ and did not fluctuate much. The eggs were turned 24 times/day.

The first incubator was set as the control group (C) and no treatment was applied to this group as part of IVP. The second incubator was assigned as the $\mathrm{HO}$ group and the ventilation system was not altered except for the provision of high $\mathrm{O}_{2}$ level into the incubator with an oxygen generator (Hikoneb Oxybreath 10LPM, Kare Medical, Ltd. Co., Turkey) and increasing $\mathrm{O}_{2}$ level. The $\mathrm{O}_{2}$ pureness of oxygenated air was $92.0 \% \pm 3.0$. Under operating conditions, the oxygen content was assumed to be about $10 \%$ lower than normal conditions, and the amount of oxygen supplied was adjusted accordingly. For the remaining two incubators air inlets were closed and $\mathrm{CO}_{2}$ was allowed to increase during the first 10 days of incubation ( $\mathrm{HO}$ and $\mathrm{HCO}$ groups). After 10 days, the air inlets were opened, and the normal ventilation programme was implemented. Air with high $\mathrm{O}_{2}$ level was let into one of these incubators (high $\mathrm{CO}_{2}+\mathrm{O}_{2}$, $\mathrm{HCO}$ ) by an oxygen generator identical to the one used for the $\mathrm{HO}$ group.

The $\mathrm{O}_{2}$ levels inside the incubators were periodically (daily) recorded by $\mathrm{O}_{2}$ data loggers (PAC 7000, Dragger Safety AG\&Co. KGaA, Deutschland), the $\mathrm{CO}_{2}$ levels by $\mathrm{CO}_{2}$ sensors (Hatch Eco 2-01, Çimuka Ltd. Co., Turkey), incubator temperature (IT) and humidity by relevant sensors (KPL215, Galtech+Mela GmbH, Germany).

On the $18^{\text {th }}$ day of incubation, the eggs were transferred from the trays to the hatch baskets of the same incubators while maintaining the layout. After the incubation was completed, EMs were determined as early stage $\left(0-5^{\text {th }}\right.$ days as EEM), middle stage $\left(6-17^{\text {th }}\right.$ days as MEM) and late stage (18-21 $1^{\text {th }}$ day) + pipped but unhatched (LPU), and the EM and HFE values were calculated from the data obtained.

\section{Statistical analysis}

The research was conducted using the random parcels trial method, and the replicate numbers were calculated by power analysis using PASS 11 (Hintze, 2011). The results were based on actual data since the differences were not significant ( $p>0.05)$ between the data with and without arcsinus transformation. Statistical analysis of the results was performed using IBM SPSS 22 (SPSS, 2013), by first obtaining the skewness and kurtosis values, and then confirming normal distribution by Shapiro-Wilk test. After this process, an analysis of variance (ANOVA) was undertaken for the experiment using the GLM procedure of SPSS appropriate for two-way designs. The two-way ANOVA model as follows:

$$
Y_{i j k}=\mu+E_{i}+I V P_{j}+(E W I V P)_{i j}+e_{i j k}
$$

Where Yijk is the dependent variable, $\mu$ is the overall mean, $\mathrm{EW}_{i}$ is the effect of EW ( $\mathrm{i}=$ heavy, medium, or light in the experiment), IVP is the effect of the IVP used ( $\mathrm{j}=$ control / $\mathrm{C}$, high $\mathrm{CO}_{2} / \mathrm{HC}$, high $\mathrm{O} 2 / \mathrm{HO}$ and high $\mathrm{CO}_{2}+\mathrm{O}_{2} / \mathrm{HCO}$ in the experiment), EWIVP is the effect of the interaction between EW and IVP, and $e_{i j k}$ is the random error term. Two-way ANOVA and post-hoc Tukey test were used to analyse the differences in the investigated parameters in relation to EW and IVP, as well as their interaction (Kocabas et al., 2013). P-values of less than 0.05 were considered as statistically significant. All the data were given as means \pm standard error of the means $(\mathrm{M} \pm \mathrm{SEM})$.

\section{RESULTS AND DISCUSSION}

Statistical analysis of the incubation data was carried out separately for the main effects EW and IVP groups, and their interactions (EW $\times$ IVP). The results are presented in the following subsections and summarised in Table 2.

\section{Egg weight}

In the first stage of the study, the EW data of the treatment groups were examined. The eggs used in the research were found to have a mean EW of 65.3 $\pm 0.1 \mathrm{~g}\left(\mathrm{CV}_{\mathrm{EW}}=6.05\right)$. The results indicated that the uniformities of EW were high, and the EW were slightly higher compared to line specs (Aviagen 2011; 64.0g).

Then, EM and hatching data were examined. The data regarding the incubation performance showed that EEM and LPU values were slightly lower to line specs (3.5 and $4.0 \%$ respectively) (Tullet, 2009). The EM and HFE values did not statistically significantly differ between the EW groups ( $p>0.05)$, and it can be stated that for the treatment range $(69.6-61.1 \mathrm{~g})$, EW did not affect EM and HFE. The EW results of the study were not in line with previous studies (Abiola et al., 2008), reporting an increase in EEM with the increased EW in age-matched flocks. This is considered to be because the differences between the EW treatment groups might not have been significant enough to affect the hatching results. 


\section{Incubator ventilation program}

Regarding the results obtained from the IVP groups, the $\mathrm{CO}_{2}$ levels were found to gradually increase during the first 10 days of incubation in the $\mathrm{HC}$ (high $\mathrm{CO}_{2}$ ) and $\mathrm{HCO}$ (high $\mathrm{CO}_{2}+$ high $\mathrm{O}_{2}$ ) groups. In relation to this treatment the $\mathrm{CO}_{2}$ levels in the incubators were found to be $0.50 \%, 0.67 \%, 1.17 \%$ and $1.57 \%$ in the $\mathrm{HO}, \mathrm{C}, \mathrm{HCO}$ and $\mathrm{HC}$ groups respectively on the $10^{\text {th }}$ day of incubation. In parallel with the increase in the $\mathrm{CO}_{2}$ levels, the $\mathrm{O}_{2}$ levels in the incubators gradually decreased, resulting in the values of $22.79 \%, 20.74 \%$, $20.34 \%$ and $20.23 \%$ in the $\mathrm{HO}, \mathrm{C}, \mathrm{HCO}$ and $\mathrm{HC}$ groups respectively (Figure 1).

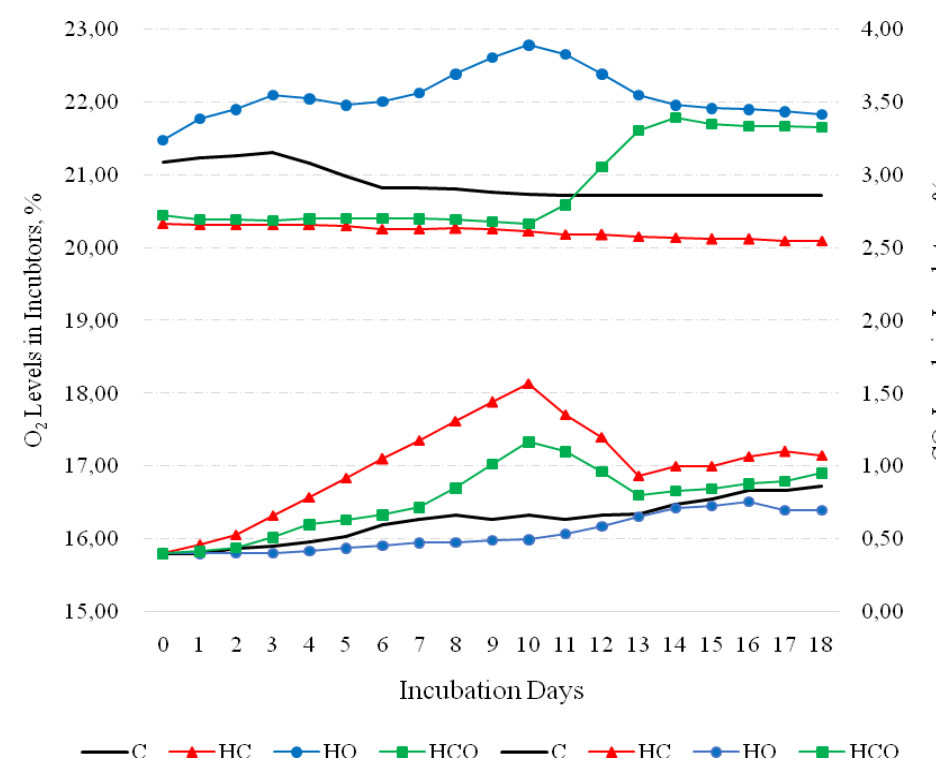

Figure 1 - The $\mathrm{CO}_{2}$ and $\mathrm{O}_{2}$ values measured in the incubators during the experiment.

It can be considered that the differences in the intra-machine $\mathrm{CO}_{2}$ and $\mathrm{O}_{2}$ levels between the IVP groups were low. However, the main aim of this study was to investigate whether these differences, which corresponded to approximately $10 \%$, had an impact on EM, and consequently on HFE. As mentioned above, many companies operate their hatcheries and broiler chick breeding farms under these conditions, and therefore it is important to determine the causes of performance loss related to the $\mathrm{CO}_{2}$ and $\mathrm{O}_{2}$ levels.

In the current study, the effects of each treatment on hatching performance were investigated based on the EM and HFE data (Table 2).

The data regarding the incubation performance showed that IVP affected EEM and consequently HFE $(p<0.05)$. For both of these parameters, the differences between the $\mathrm{HO}$ and $\mathrm{HCO}$ groups were statistically significant $(p<0.05)$. In addition, the HFE differences between the $\mathrm{C}$ and $\mathrm{HO}$ groups were significant $(p<0.05)$ due to the numerically evident differences between the LPU. However, there was no significant difference between the groups in the remaining hatching parameters of even the eggs of same age and from the same flock. This is considered to be because eggshell conductance and pore structure changed due to the gaseous composition and barometric pressure of ambient fresh air, and potential adverse effects were physiologically avoided at these levels.

\section{Egg weight and incubator ventilation program interaction}

The EW $x$ IVP interaction had a significant effect on EEMs $(p<0.05)$. The rate of EEMs was even higher for light hatching eggs incubated in the $\mathrm{HO}$ (high $\mathrm{O}_{2}$ ) (Table 2). However, there were no statistically significant differences for the LSPU and HFE parameters between the IVP groups ( $p>0.05)$.

The difference between the EEMs in the $\mathrm{HO}$ (high $\mathrm{O}_{2}$ ) and $\mathrm{HCO}$ (high $\mathrm{CO}_{2}+$ high $\mathrm{O}_{2}$ ) groups $(22.79 \%$ and $20.74 \%$ respectively) indicate that an $\mathrm{O}_{2}$ value greater than the normal level is harmful in early stage of incubation. The results of higher rates of EEMs in $\mathrm{HO}$ group are consistent with those of other researchers (Taylor et al., 1971; Everaert et al., 2007), reporting increased $\mathrm{O}_{2}$ tolerance over time.

EEM were numerically lower in all light egg treatment groups than the heavy and medium egg treatment groups, some with statistical significance; thus, higher HFE values were achieved. This can be attributed to the change in eggshell conductance depending on EW. In this respect, the current results support those found in the literature (Ar et al., 1974).

In contrast to the findings of the current research other studies reported that gradually increasing the $\mathrm{CO}_{2}$ levels from $1.00 \%$ to $1.50 \%$ within the first 10 days of incubation improved embryonic growth, encouraged early hatching and increased $\mathrm{H}$ in turkey and chicken eggs (Tona et al., 2007). Similarly, the current research is not in line with the previous results suggesting that $\mathrm{CO}_{2}$ values over $1 \%$ inside the machine during the early period of incubation negatively affects hatch results (Romanoff, 1936). As suggested by Visschedijk (1991), this may be due to the functional conductance of eggshell along with gaseous composition and barometric pressure of the ambient fresh air.

In relation to the altitude of the study area (724 $\mathrm{m})$, the findings of the research support the reports of breeder companies suggesting that hatcheries should be established in areas at a maximum altitude of 750 m (Cobb, 2013) or 1500 m (Tullet, 2013), to ensure 
Table 2 - The effects of egg weight, incubator ventilation program on broilers' embryo mortality and hatchability of fertile eggs (HFE) (M \pm SEM).

\begin{tabular}{|c|c|c|c|c|}
\hline & \multicolumn{3}{|c|}{ Embryo Mortality, \% } & \multirow{2}{*}{$\begin{array}{c}\text { Hatchability } \\
\text { of Fertile Eggs, \% }\end{array}$} \\
\hline & $\begin{array}{c}\text { Early Stage } \\
0-5 \text { day }\end{array}$ & $\begin{array}{l}\text { Mid Stage } \\
6-17 \text { day }\end{array}$ & Late Stage + Pipped but Unhatched & \\
\hline \multicolumn{5}{|l|}{ Main Effect } \\
\hline \multicolumn{5}{|l|}{ Egg Weight, g } \\
\hline Heavy $(69.63 \pm 0.09 \mathrm{~g})$ & $1.62 \pm 0.58$ & $0.70 \pm 0.37$ & $3.04 \pm 0.51$ & $94.62 \pm 0.58$ \\
\hline Medium $(65.20 \pm 0.04 \mathrm{~g})$ & $2.33 \pm 0.67$ & $0.70 \pm 0.39$ & $2.11 \pm 0.48$ & $94.84 \pm 0.84$ \\
\hline Light $(61.11 \pm 0.08 \mathrm{~g})$ & $1.57 \pm 0.58$ & $0.55 \pm 0.30$ & $1.31 \pm 0.44$ & $96.27 \pm 0.76$ \\
\hline \multicolumn{5}{|c|}{ Incubator Ventilation Program } \\
\hline C & $1.55 \pm 0.72^{\mathrm{ab}}$ & $0.21 \pm 0.21$ & $2.17 \pm 0.55$ & $96.26 \pm 0.65^{a}$ \\
\hline $\mathrm{HC}$ & $2.16 \pm 0.72^{\mathrm{ab}}$ & $1.04 \pm 0.55$ & $2.08 \pm 0.71$ & $94.72 \pm 1.07^{\mathrm{ab}}$ \\
\hline $\mathrm{HO}$ & $3.12 \pm 0.78^{a}$ & $0.52 \pm 0.36$ & $2.18 \pm 0.56$ & $93.42 \pm 0.69^{b}$ \\
\hline $\mathrm{HCO}$ & $0.52 \pm 0.36^{b}$ & $0.82 \pm 0.44$ & $2.17 \pm 0.55$ & $96.57 \pm 0.72^{\mathrm{a}}$ \\
\hline \multicolumn{5}{|l|}{ Interaction (EW X IVP) } \\
\hline Heavy C & $0.93 \pm 0.93^{\mathrm{bc}}$ & $0.00 \pm 0.00$ & $1.89 \pm 1.09$ & $96.26 \pm 1.51$ \\
\hline Heavy HC & $3.70 \pm 1.51^{\mathrm{ab}}$ & $0.96 \pm 0.96$ & $3.74 \pm 1.51$ & $93.45 \pm 0.95$ \\
\hline Heavy HO & $0.93 \pm 0.93^{b c}$ & $0.93 \pm 0.93$ & $2.81 \pm 0.94$ & $94.41 \pm 1.05$ \\
\hline Heavy HCO & $0.93 \pm 0.93^{b c}$ & $0.93 \pm 0.93$ & $3.70 \pm 0.00$ & $94.37 \pm 1.03$ \\
\hline Medium C & $3.74 \pm 1.51^{\mathrm{ab}}$ & $0.64 \pm 0.64$ & $2.78 \pm 0.93$ & $95.34 \pm 0.94$ \\
\hline Medium HC & $1.85 \pm 1.07^{\mathrm{abc}}$ & $1.23 \pm 1.23$ & $1.89 \pm 1.09$ & $94.41 \pm 1.84$ \\
\hline Medium $\mathrm{HO}$ & $3.74 \pm 1.51^{\mathrm{ab}}$ & $0.00 \pm 0.00$ & $2.81 \pm 0.94$ & $91.49 \pm 1.01$ \\
\hline Medium HCO & $0.00 \pm 0.00^{c}$ & $0.93 \pm 0.93$ & $0.96 \pm 0.96$ & $98.11 \pm 1.09$ \\
\hline Light C & $0.00 \pm 0.00^{c}$ & $0.00 \pm 0.00$ & $1.85 \pm 1.07$ & $97.19 \pm 0.94$ \\
\hline Light HC & $0.93 \pm 0.93^{b c}$ & $0.93 \pm 0.93$ & $0.62 \pm 0.62$ & $96.30 \pm 2.62$ \\
\hline Light HO & $4.70 \pm 1.00^{a}$ & $0.64 \pm 0.64$ & $0.93 \pm 0.93$ & $94.37 \pm 1.11$ \\
\hline Light HCO & $0.64 \pm 0.64^{c}$ & $0.62 \pm 0.62$ & $1.85 \pm 1.07$ & $97.22 \pm 0.93$ \\
\hline \multicolumn{5}{|l|}{$p$ number } \\
\hline EW & 0.511 & 0.951 & 0.060 & 0.183 \\
\hline IVP & 0.030 & 0.585 & 0.999 & 0.024 \\
\hline EW XIVP & 0.023 & 0.967 & 0.447 & 0.339 \\
\hline
\end{tabular}

EW: Egg Weight, IVP: Incubator ventilation program, C: Control $\left(0.7 \% \mathrm{CO}_{2}\right.$ and $\left.20.9 \% \mathrm{O}_{2}\right)$, $\mathrm{HC}$ : High $\mathrm{CO}_{2}\left(1.1 \% \mathrm{CO}_{2}\right.$ and $\left.20.3 \% \mathrm{O}_{2}\right)$, $\mathrm{HO}$ : High $\mathrm{O}_{2}\left(0.6 \% \mathrm{CO}_{2}\right.$ and $\left.22.0 \% \mathrm{O}_{2}\right)$, $\mathrm{HCO}$ : High $\mathrm{CO}_{2}+\mathrm{O}_{2}\left(0.9 \% \mathrm{CO}_{2} 21.0 \% \mathrm{O}_{2}\right)$.

abc Different superscript letters show that difference between means of groups are statistically significant $(p<0.05)$.

that the HFE values are not negatively affected. This is because at lower altitudes, there is less in the $\mathrm{O}_{2}$ and $\mathrm{CO}_{2}$ levels during the incubation period, as also confirmed by the results of the current study. Therefore, for areas at a similar altitude of the studied area $(724 \mathrm{~m})$, the use of an $\mathrm{O}_{2}$ concentrator is not necessary considering that the amount of changes in the $\mathrm{CO}_{2}$ and $\mathrm{O}_{2}$ levels especially in the first 10 days of incubation, $1.70 \%$ and $22.69 \%$ respectively, did not have any effect on EM in the current research.

\section{CONCLUSION}

The overall results of the experiment revealed that using an oxygen concentrator is not necessary at the altitude of $724 \mathrm{~m}$, and the $\mathrm{CO}_{2}$ and the $\mathrm{O}_{2}$ levels affected the hatching parameters, especially in light eggs. It is suggested that further investigations should concentrate on the effects of similar applications on embryo development (tissue, organ etc.) and field performance to provide more detailed and useful data. This is especially important for large-scale integrated companies operating high-capacity industrial incubators at different altitude levels in which oxygen levels changed.

\section{ACKNOWLEDGMENTS}

The author thanks Beypi Inc. (beypiliç) for providing the hatching eggs used in the experiment and the department of B.A.I.B.U. B.A.P. for funding and supporting the project. The author is also grateful to Dr. Sabri Arda Eratalar for his kind spirit and support in every stage of the study.

\section{REFERENCES}

Abiola SS, Meshioye OO, Oyerinde BO, Bamgbose MA. Effect of egg size on hatchability of broiler chicks. Archivos Zootechnica 2008;57(217):8386. 
Ar A, Paganelli CV, Reeves RB, Greene DG, Rahn H. The avian egg: water vapour conductance, shell thickness and functional pore area. The Condor 1974;76:153-158

Ahmed M, Biswas A, Roy BG, Srivastava RB. Frequently encountered problems during hatching in cold arid high altitude regions such as Ladakh in India:causes and remedies. World's Poultry Science Journal 2013;69(4):897-901.

Aviagen. Ross 308 parent stock: performance objectives. Newbrdige Midlothian, EH28 8SZ, Scotland, UK, 2011.

Bamelis FR. Non-Invasive assessment of eggshell conductance at different developmental stages during incubation of eggs [thesis]. Leuven (BE): Catholic University; 2003.

Buys N, Dewil E, Gonzales E, Decuypere E. Different $\mathrm{CO}_{2}$ levels during incubation interact with hatching time and ascites susceptibility in two broiler lines selected for different growth rate. Avian Pathology 1998;27(6):605-612

Celen F, Yildirim I, Parlat SS, Alkis, E. The effects of broiler breeder age and extra oxygen addition into incubation at high altitude $(1700 \mathrm{~m})$ on hatching results and subsequent performance in broilers. Journal of Animal and Veterinary Advances 2009;8(7):1438-1442.

Cobb. Cobb hatchery management guide [publication L-1030-03]. Arkansas: Cobb-Vantress; 2013.

Decuypere E, Tona K, Bruggeman V, Bamelis F. The day-old chick:a crucial hinge between breeders and broilers. Worlds Poultry Science Journal 2001;57(2):127-138

De Smit L, Bruggeman V, Debonne M, Tona JK, Kamers B, Everaert N, et al. The effect of nonventilation during early incubation on the embryonic development of chicks of two commercial broiler strains differing in ascites susceptibility. Poultry Science 2008;87(3):551-560.

Elibol O, Brake J. Effect of egg weight and position relative to incubator fan on broiler hatchability and chick quality. Poultry Science 2008;87(9):1913-1918.

Elibol O, Turkoglu M. Embryo development and hatchery. In:Turkoglu M, Sarica M, editors. Poultry science. $4^{\text {th }}$ ed. Ankara: Bey Ofset; 2014. p.200-206

Everaert N, Kamers B, Witters A, De Smit L, Debonne M, Decuypere E, et al. Effect of four percent carbon dioxide during the second half of incubation on embryonic development, hatching parameters and posthatch growth. Poultry Science 2007;86(7):1372-1379.

Fernandes J, Bortoluzzi C, Esser AFG, Contini JP, Stokler PB, Faust D. Performance of broilers submitted to high $\mathrm{CO}_{2}$ levels during incubation combined with temperature fluctuations at late pot-hatch. Brazilian Journal of Poultry Science 2014;16(3):285-290.

Hintze JL. Pass 11. Kaysville; 2011.

Huwaida EE, Sakin MAIY, Elagib HAA, Bakhiet E, Dousa BM, Elamin KM. Effect of egg weight and egg shell thickness on hatchability and embryonic mortality of Cobb broiler breeder eggs. Global Journal of Animal Scientific Research 2015;3(1):186-190.

Joseph NS, Lourens A, Moran JR. The effects of suboptimal eggshell temperature during incubation on broiler chick quality, live performance, and further processing yield. Poultry Science 2006;85(5):932-938.

Kocabas Z, Ozkan M, Baspinar E. Basic biometry. Ankara: Ankara University Faculty of Agriculture; 2013.

Lourens A, Brand $H$, Meijerhof R, Kemp B. Effect of eggshell temperature during incubation on embryo development, hatchability, and posthatch development. Poultry Science 2005;84(6):914-920.
Lourens A, Van Den Brand H, Hetkamp MJW, Meijerhof R, Kemp B. Effects of egg shell temperature and oxygen concentration on embryo growth and metabolism during incubation. Poultry Science 2007;86(10):21942199.

Maatjens CM, Reijrink AM, Molenaar R, Van Der Pol CW, Kemp B, Van Den Brand $\mathrm{H}$. Temperature and $\mathrm{CO}_{2}$ during the hatching phase. I. Effects on chick quality and organ development. Poultry Science 2014a;93(3):645-654

Maatjens CM, Reijrink AM, Molenaar R, Van Der Pol CW, Kemp B, Van Den Brand $\mathrm{H}$. Temperature and $\mathrm{CO}_{2}$ during the hatching phase. II. Effects on chicken embryo physiology. Poultry Science 2014b;93(3):655-663.

Meijerhof R. The influence of incubation on chick quality and broiler performance. Proceeding of $20^{\text {th }}$ Australia Poultry Science Symposium: 2009; New South Wales, Sydney. Australia; 2009. p. 106-111.

Molenaar R, Meijerhof R, Van Den Anker I, Heetkamp MJW, Van Den Borne JJGC, Kemp B, Van Den Brand H. Effect of eggshell temperature and oxygen concentration on survival rate and nutrient utilization in chicken embryos. Poultry Science 2010;89(9):2010-2021.

Onagbesan O, Bruggeman V, De Smit L, Debonne M, Witters A, Tona K, et al. Gas exchange during storage and incubation of avian eggs:effects on embryogenesis, hatchability, chick quality and post-hatch growth. World's Poultry Science Journal 2007;63(4):557-573.

Ozlu S, Ucar A, Banwell R, Elibol O. The effect of increased concentration of carbon dioxide during the first 3 days of incubation on albumen characteristics, embryonic mortality and hatchability of broiler hatching eggs. Poultry Science 2019;98(4):771-776.

Piestun Y, Shinder D, Ruzal M, Halevy O, Brake J, Yahav S. Thermal manipulations during broiler embryogenesis:effect on the acquisition of thermotolerance. Poultry Science 2008;87(8):1516-1525.

Romanoff AL. Effects of different temperatures in the incubator on the prenatal and postnatal development of the chick. Poultry Science 1936;15:311-315.

SPSS. SPSS release 22.0 statistical packet program, SPSS for windows. Chicago; 2013.

Stock MK, Metcalfe J. Stimulation of growth of the chick embryo by acute hyperoxia. Respiration Physiology 1984;58(3):351-358.

Taylor LW, Kreutziger GO, Abercrombie GL. The gaseous environment of the chick embryo in relation to its development and hatchability. 5. Effects of carbon dioxide and oxygen levels during the terminal days of incubation. Poultry Science 1971;50(1):66-78.

Tona K, Onagbesan O, Bruggeman V, De Smit L, Figueiredo D, Decuypere E. Non-ventilation during early incubation in combination with dexamethasone administration during late incubation. 1. Effects on physiological hormone levels, Incubation duration and hatching events. Domestic Animal Endocrinology 2007;33(1):32-46.

Tona K, Everaert N, Willemsen H, Gbeassor M, Decuypere E, Buyse J. Effects of interaction of incubator $\mathrm{CO}_{2}$ levels and mixing hatching eggs of different embryo growth trajectory on embryo physiological and hatching parameters. British Poultry Science 2013;54(4):545-551.

Tong Q, Mc Gonnell M, Romanini CEB, Bergoug H, Roulston N, Exadaktylos $\mathrm{V}$, et al. Higher levels of $\mathrm{CO}_{2}$ during late incubation alter the hatch time of chicken embryos. British Poultry Science 2015;56(4):503-509.

Tullet S. Hatchery Ross Tech: investigating hatchery practice. Newbridge: Aviagen; 2009.

Tullet S. Incubating eggs at high altitude [ross technote 0713-AVNR-027]. Newbridge: Aviagen; 2013.

Visschedijk AH. Gordon memorial lecture. Physics and physiology of incubation. British Poultry Science 1991;32(1):3-20. 
